\title{
Addition of dipeptidyl peptidase-4 inhibitors to sulphonylureas and risk of hypoglycaemia: systematic review and meta-analysis
}

\author{
Francesco Salvo, 1, 2, 3 Nicholas Moore, 1, 2,3,4 Mickael Arnaud, 1, 2 Philip Robinson,, , 5 \\ Emanuel Raschi, ${ }^{6}$ Fabrizio De Ponti, ${ }^{6}$ Bernard Bégaud,1, 2,3 Antoine Pariente1, 2,3
}

1 University of Bordeaux, UMR1219, F-33000 Bordeaux, France

2INSERM, UMR1219, Bordeaux Population Health Research Center, Pharmacoepidemiology team, Bordeaux, France

${ }^{3} \mathrm{CHU}$ Bordeaux, Bordeaux, France

${ }^{4} \mathrm{ClC}$ Bordeaux $\mathrm{ClC} 1401$ Bordeaux, France

${ }^{5}$ ADERA, Pessac, France

${ }^{6}$ Department of Medical and

Surgical Sciences, University of Bologna, Bologna, Italy

Correspondence to: F Salvo francesco.salvo@u-bordeaux.fr Additional material is published online only. To view please visit the journal online.

Cite this as: $B M J$ 2016;353:i2231 http://dx.doi.org/10.1136/bmj.i2231

Accepted: 6 April 2016

\begin{abstract}
OBJECTIVE

To quantify the risk of hypoglycaemia associated with the concomitant use of dipeptidyl peptidase-4 (DPP-4) inhibitors and sulphonylureas compared with placebo and sulphonylureas.
\end{abstract}

DESIGN

Systematic review and meta-analysis.

DATA SOURCES

Medline, ISI Web of Science, SCOPUS, Cochrane

Central Register of Controlled Trials, and clinicaltrial. gov were searched without any language restriction.

\section{STUDY SELECTION}

Placebo controlled randomised trials comprising at least 50 participants with type 2 diabetes treated with DPP-4 inhibitors and sulphonylureas.

\section{REVIEW METHODS}

Risk of bias in each trial was assessed using the Cochrane Collaboration tool. The risk ratio of hypoglycaemia with $95 \%$ confidence intervals was computed for each study and then pooled using fixed effect models (Mantel Haenszel method) or random effect models, when appropriate. Subgroup analyses were also performed (eg, dose of DPP-4 inhibitors). The number needed to harm (NNH) was estimated according to treatment duration.

RESULTS

10 studies were included, representing a total of 6546 participants (4020 received DPP-4 inhibitors plus sulphonylureas, 2526 placebo plus sulphonylureas). The risk ratio of hypoglycaemia was 1.52 (95\% confidence interval 1.29 to 1.80). The NNH was 17 (95\% confidence interval 11 to 30) for a treatment duration of six months or less, 15 (9 to 26) for 6.1 to 12 months, and 8 ( 5 to 15 ) for more than one year. In subgroup analysis, no difference was found between full and low

\section{WHAT IS ALREADY KNOWN ON THIS TOPIC}

Hypoglycaemia is a serious event that could be related to increased morbidity and mortality in people with type 2 diabetes

The risk of hypoglycaemia is known to increase when dipeptidyl peptidase- 4 (DPP-4) inhibitors are used concomitantly with sulphonylureas

However, the magnitude of this risk has not yet been measured

\section{WHAT THIS STUDY ADDS}

Addition of DPP-4 inhibitors to sulphonylurea in people with type 2 diabetes is associated with a $50 \%$ increased risk of hypoglycaemia and to one excess case for every 17 patients in the first six months of treatment

Thus the recommendations for a reduction of sulphonylurea dose when initiating DPP-4 inhibitors must be followed, even though the effectiveness of this risk minimisation strategy has not yet been assessed doses of DPP-4 inhibitors: the risk ratio related to full dose DPP-4 inhibitors was 1.66 (1.34 to 2.06), whereas the increased risk ratio related to low dose DPP-4 inhibitors did not reach statistical significance (1.33, 0.92 to 1.94 ).

\section{CONCLUSIONS}

Addition of DPP-4 inhibitors to sulphonylurea to treat people with type 2 diabetes is associated with a $50 \%$ increased risk of hypoglycaemia and to one excess case of hypoglycaemia for every 17 patients in the first six months of treatment. This highlights the need to respect recommendations for a decrease in sulphonylureas dose when initiating DPP-4 inhibitors and to assess the effectiveness of this risk minimisation strategy.

\section{Introduction}

Hypoglycaemia is a potentially life threatening event associated with an increased risk of hospital admission, ${ }^{1}$ cardiovascular disease, and mortality. ${ }^{23}$ The ACCORD (Action to Control Cardiovascular Disease in Diabetes) trial of intensive glucose lowering in people with type 2 diabetes found a 2.5 -fold increase in hypoglycaemic events. That trial was prematurely stopped owing to increased mortality possibly related to the unfavourable effect of hypoglycaemia in susceptible participants, such as those with underlying coronary diseases. ${ }^{45}$

Hypoglycaemia has emerged as a leading complication of diabetes in older adults ( $>60$ years) with a longer history of the disease. It is the second cause of admission to hospital in people with type 2 diabetes, ${ }^{6}$ accounts for $20-25 \%$ of hospital admissions for adverse drug reactions, ${ }^{17}$ and might precipitate heart failure in those at greatest risk. ${ }^{8}$ More generally, it can result in falls and fractures in people aged 65 years or more, ${ }^{9}$ has a negative effect on quality of life, ${ }^{1011}$ and, in the long term, may impair the maintenance of euglycaemia and the full benefit of treatments. ${ }^{12}$ Moreover, the importance of mild to moderate (iatrogenic) hypoglycaemia should not be overlooked as this may lead to unawareness of the hypoglycaemia (through altered adrenergic response to the condition). ${ }^{13-15}$ This may compromise behavioural defences (hunger resulting in carbohydrate ingestion) and increase the risk of recurrent episodes and severe hypoglycaemia. ${ }^{16} 17$ Therefore, hypoglycaemia is a serious adverse event that must be considered when studying the safety of glucose lowering drugs.

Dipeptidyl peptidase-4 (DPP-4) inhibitors are a recently marketed class of oral glucose lowering drugs. They are indicated as second line treatment in people with type 2 diabetes mellitus not adequately responsive 
or intolerant to metformin, or in whom other glucose lowering drugs (such as sulphonylureas or thiazolidinediones) do not achieve glycaemic control. These drugs have different mechanisms of action. For instance, target tissue sensitivity to insulin is increased by thiazolidinediones, ${ }^{18}$ hepatic gluconeogenesis is suppressed by metformin, ${ }^{19}$ and insulin secretion is increased indirectly by DPP-4 inhibitors (through the inhibition of incretin catabolism ${ }^{20}$ ) and directly by sulphonylureas. $^{2122}$

Several randomised clinical trials have studied DPP-4 inhibitors both as monotherapy and, more often, in patients treated with other glucose lowering drugs, metformin in particular, but also thiazolidinediones and sulphonylureas. ${ }^{23}$ When DPP-4 inhibitors have been used as monotherapy, the incidence of hypoglycaemia was comparable to that of placebo or metformin (around 5\%),2425 and a number of randomised controlled trials indicate that this risk is not increased when DPP-4 inhibitors are used in patients treated with metformin or thiazolidinediones, thus confirming their acceptable safety profile. ${ }^{2326}$

Conversely, when DPP-4 inhibitors are used with sulphonylureas, an increased incidence of hypoglycaemia has been noted. ${ }^{2728}$ This could be related to the higher incidence of hypoglycaemia among patients treated with sulphonylureas (about 20\%, which increases with treatment duration), ${ }^{29}$ which is further increased when patients are treated by a second drug acting on insulin secretion. Although the summaries of the product characteristics of DPP-4 inhibitors acknowledge the increased risk of hypoglycaemia due to this association, ${ }^{30-34}$ this risk remains insufficiently assessed. We carried out a meta-analysis to quantify the risk of hypoglycaemia associated with the use of DPP-4 inhibitors and sulphonylureas in people with type 2 diabetes mellitus.

\section{Methods}

\section{Eligibility criteria}

Clinical trials eligible for this meta-analysis were those that: studied the effect of adding one DPP-4 inhibitor to sulphonylureas, with or without other oral glucose lowering drugs, in people with type 2 diabetes; studied one DPP-4 inhibitor used at daily doses approved in clinical practice-alogliptin (Takeda Pharmaceutical), linagliptin (Boehringer Ingelheim), saxagliptin (Astrazeneca), sitagliptin (Merck Sharp \& Dohme), and vildagliptin (Novartis); were randomised; were controlled with placebo and sulphonylureas; and included at least 50 participants treated with DPP-4 inhibitors. Reports concerning extension phases of randomised controlled trials were not eligible.

\section{Patient involvement}

No patients were involved in setting the research question or the outcome measures, nor were they involved in developing plans for design or implementation of the study. No patients were asked to advise on interpretation or writing up of results. There are no plans to disseminate the results of the research to study participants or the relevant patient community.

\section{Search strategy}

We searched Medline, ISI Web of Science, SCOPUS, and the Cochrane Central Register of Controlled Trials on 15 October 2013 using keywords related to DPP-4 inhibitors and randomised controlled trials (see supplementary file for a detailed list of keywords used to search Medline). In addition, we screened articles in the "Related citations in PubMed" section, and conducted a snowballing procedure to examine the references cited in systematic reviews and meta-analyses retrieved through the systematic search. We also periodically checked Clinicaltrials.gov (last search November 2014) to identify unpublished but eligible trials. No time or language restriction was applied to the searches. EndNote X6 for Macintosh (Thomson Reuters) was used to compile the bibliography.

\section{Study selection}

Two authors (FS and AP) independently reviewed and screened the title and abstract of potentially relevant randomised controlled trials and determined final eligibility through examination of full texts. Disagreements were resolved through discussion. Each eligible randomised controlled trial was checked for the number of participants treated with DPP-4 inhibitors plus sulphonylureas and placebo plus sulphonylureas, and for the number of participants with at least one episode of hypoglycaemia in each treatment group. If such data were unavailable in the full text, we emailed the authors or study contacts for the information.

\section{Data extraction}

Two authors (FS and AP) independently extracted information on the methods (study design, study duration, and use of other glucose lowering drugs allowed); participants' age, sex, country, setting, and baseline mean glycated haemoglobin $\mathrm{A}_{1 \mathrm{C}}\left(\mathrm{HbA}_{1 \mathrm{c}}\right)$ level; intervention (DPP-4 inhibitors and sulphonylureas international non-proprietary names, daily doses, and number of treated patients); and definition of hypoglycaemia. Disagreements were resolved through discussion or revision of the full text.

\section{Quality assessment and evidence of quality}

Using the Cochrane Collaboration tool for assessing risk of bias in randomised trials, we determined the quality of the included studies through examination of the full text or the original study protocol (as published or reported in clinicaltrial.gov). ${ }^{35}$ Quality assessment considered random sequence generation; allocation concealment; blinding of participants, staff, and outcome assessors; incomplete outcome data; selective outcome reporting; and other potential biases. The risk of bias for each of these items was assessed as high, low, or unknown. We used the GRADE framework to determine the strength of evidence of the meta-analysis. ${ }^{36}$ This approach is used to contextualise or justify recommendations; it grades the quality of evidence resulting from a meta-analysis from very low to high, which corresponds to how likely further research might alter conclusions drawn from the current evidence. 
"High quality" suggests that it is very unlikely for conclusions about effect estimates to change, whereas "very low quality" means it is very likely for conclusions about effect estimates to change. ${ }^{37}$

The study was reported in accordance with the preferred reporting items for systematic reviews and meta-analyses (PRISMA) statement (see supplementary file for research checklist). ${ }^{38}$

\section{Statistical analysis}

We compared the risk of hypoglycaemia in patients treated with DPP-4 inhibitors plus sulphonylureas with that in patients treated with placebo plus sulphonylureas. All studies meeting the inclusion criteria were included in the quantitative analysis, irrespective of quality. ${ }^{35}$

For each study, we computed the risk ratio for hypoglycaemia along with the $95 \%$ confidence interval. The pooled risk ratio was computed using fixed effect models (Mantel Haenszel method) ${ }^{39}$ or, in the event of statistically significant heterogeneity between estimates, random effect models. ${ }^{40}$ We used the Mantel Haenszel method as it has been shown to have better statistical properties than inverse variance methods when the included studies report few events, ${ }^{41}$ which is the case in a meta-analysis investigating the risk of hypoglycaemia in trials primarily studying the efficacy of glucose lowering drugs. Statistical heterogeneity among studies was evaluated using the Cochran $\mathrm{Q}$ test $(\mathrm{P}<0.10$ considered to be significant), and the $\mathrm{I}^{2}$ index used to estimate the proportion of total variation contributed by variance between studies. ${ }^{42}$ All P values were two sided.

The primary analysis concerned all studies meeting the inclusion criteria; secondary analyses were performed classifying the DPP-4 inhibitors doses into full and low daily dose (as mentioned in the corresponding summaries of the product characteristics, low daily doses are mostly recommended in patients with renal impairment; see supplementary table 1), and according to the presence of a clear definition of hypoglycaemia. The forest plot of each analysis presents the subgroups that were compared using the Cochran $\mathrm{Q}$ test across subgroup results, rather than across individual study results. We also computed an $\mathrm{I}^{2}$ index for subgroup differences; this describes the percentage of the variability in effect estimates from the different subgroups that is due to genuine differences between the subgroups rather than to sampling error (eg, chance). ${ }^{41}$ Moreover, we conducted sensitivity analyses by excluding studies with a high risk of bias (that is, at least one item), studies allowing the use of insulin, or studies for which one or more patients characteristics were imbalanced among groups.

Publication bias was evaluated by using a funnel plot and Egger's regression test $(\mathrm{P}<0.05$ considered to be significant). ${ }^{43}$ We estimated the number of patients needed to be treated to observe one harmful outcome (number needed to harm, NNH) according to the Cochrane recommendations. ${ }^{44}$ On the assumption that the incidence of hypoglycaemia is related to the length of follow-up, we calculated the assumed control risk for different follow-up scenarios: six months or less, 6.1 to 12 months, and more than one year. ${ }^{44}$

The analyses were conducted with Review Manager software (RevMan version 5.3, Nordic Cochrane Centre, Cochrane Collaboration) and R software (version 2.15.3).

All relevant aspects related to the search strategy, study selection, data extraction and quality assessment, and data analysis were specified in a synopsis protocol detailing the meta-analysis objective and context, and the principles and modalities of the literature search and the data analysis were developed.

\section{Results}

\section{Study selection}

The electronic search identified 2379 records, 687 of which were duplicates and removed. Fifteen records were retrieved through other sources. The title and abstract of 1707 individual study records were assessed, 1650 of which were irrelevant and therefore excluded. The remaining 57 records underwent full text examination (see supplementary file for details); 10 studies were finally included in this meta-analysis (fig 1). ${ }^{27} 4546-53$

\section{Study characteristics}

The 10 included studies comprised a total of 6456 participants, 4020 of whom received DPP-4 inhibitors plus sulphonylureas and 2526 placebo plus sulphonylureas. All the studies were randomised and double blinded. One study included only participants aged 70 years or more. $^{27}$

In nine of the 10 studies the planned follow-up was 24 weeks or less (or less than six months); one study followed patients for a median drug use time of 76 weeks

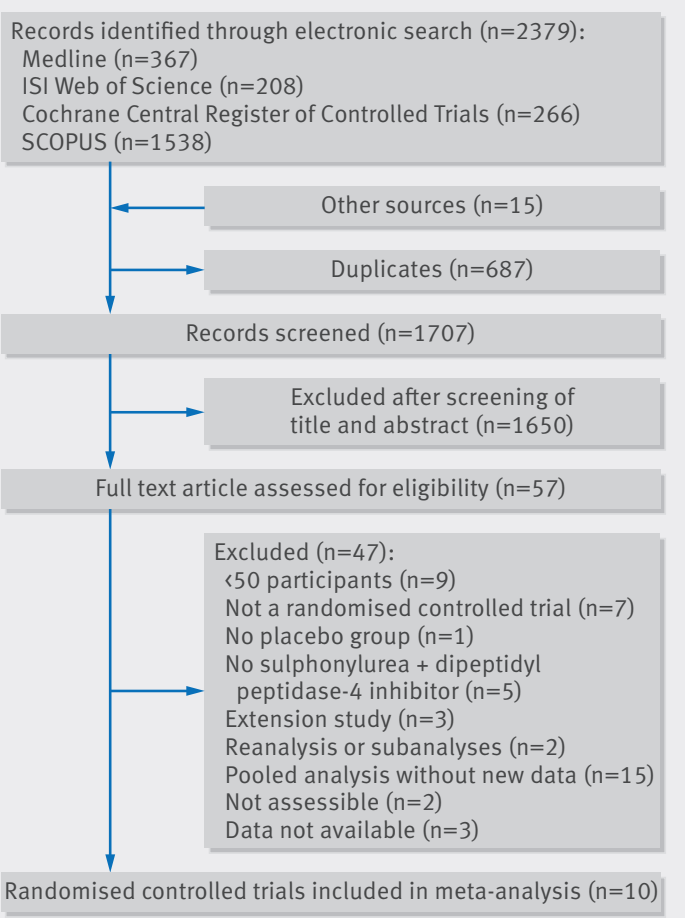

Fig 1 | Flow diagram of study identification, selection, and inclusion 
(around 16 months). In view of these data, it was not possible to provide specific NNHs for the scenarios of follow-up duration. Therefore, the assumed control risk of hypoglycaemia in patients treated with sulphonylureas was calculated from another meta-analysis, ${ }^{29}$ which included 27 clinical trials. According to study follow-up, the assumed control risk was $11.6 \%$ for follow-up of six months or less (seven studies), 13.3\% from 6.1 to 12 months (nine studies), and $22.8 \%$ for more than one year (11 studies; see supplementary table 2 for details of these studies).

The type of associated sulphonylureas varied across the trials (table 1). In four, drug treatment also included metformin. ${ }^{27} 475053$ In two, use of insulin was allowed. ${ }^{2753}$ Baseline key patient characteristics (namely, mean glycated haemoglobin $\mathrm{A}_{1 \mathrm{C}}$, mean age, and sex) were well balanced among the patients in each of the groups, with the exception of two studies $^{27} 49$ in which there was an apparent difference in sex ratio (table 1 ).

Three randomised controlled trials studied linagliptin $5 \mathrm{mg} /$ day in a total of 1038 patients. ${ }^{27} 4950$ Vildagliptin $100 \mathrm{mg} /$ day ( $\mathrm{n}=271$ participants) was studied in two trials $^{4648}$ and vildagliptin $50 \mathrm{mg} /$ day $(\mathrm{n}=170)$ in one trial. ${ }^{46}$ Alogliptin was studied once at $12.5 \mathrm{mg} /$ day $(n=308)$ and once at $25 \mathrm{mg} /$ day $(\mathrm{n}=302) . .^{5152}$ One trial studied alogliptin at different doses (from $6.5 \mathrm{mg} /$ day to $25 \mathrm{mg} /$ day) in 1198 patients receiving sulphonylureas. ${ }^{53}$ Saxagliptin $(2.5 \mathrm{mg} / \text { day }(\mathrm{n}=248) \text { and } 5 \mathrm{mg} / \text { day }(\mathrm{n}=253))^{45}$ and sitagliptin $100 \mathrm{mg} /$ day $(\mathrm{n}=222)^{47}$ were each studied once. Overall, 2526 patients receiving placebo plus sulphonylureas were identified in the 10 included trials (table 1). Six of the 10 trials failed to clearly report the definition of hypoglycaemia (table 1). 454749505253

The risk of reporting bias was high in three of the studies; ${ }^{46-48}$ one trial also presented a high risk of detection bias (fig 2, see supplementary file for details). ${ }^{47}$

Overall, 4020 patients received DPP-4 inhibitors (2096 at full dose, 726 at low dose, and 1198 at undefined dose) plus sulphonylureas, 479 of whom developed hypoglycaemia (311 at full dose, 67 at low dose, and 101 at undefined dose) corresponding to an absolute risk of $11.9 \%$. In total, 2526 received placebo plus sulphonylureas, 169 of whom developed hypoglycaemia, corresponding to an absolute risk of $6.7 \%$.

\begin{tabular}{|c|c|c|c|c|c|c|c|}
\hline References & $\begin{array}{l}\text { Study duration } \\
\text { (weeks) }\end{array}$ & $\begin{array}{l}\text { Intervention, daily dose } \\
\text { (No of patients) }\end{array}$ & $\begin{array}{l}\text { Associated } \\
\text { sulphonylureas }\end{array}$ & $\begin{array}{l}\text { Mean haemoglobin } \\
\mathrm{A}_{1 \mathrm{c}} \text { at baseline (\%) }\end{array}$ & $\begin{array}{l}\text { Mean age of } \\
\text { participants (years) }\end{array}$ & Male (\%) & $\begin{array}{l}\text { Definition of } \\
\text { hypoglycaemia }\end{array}$ \\
\hline Barnett et al ${ }^{27}$ & 24 & $\begin{array}{l}\text { Linagliptin } 5 \mathrm{mg}(n=95) \text { or } \\
\text { placebo }(n=43)\end{array}$ & $\begin{array}{l}\text { Sulphonylureas, not } \\
\text { specified }\end{array}$ & $\begin{array}{l}\text { DPP-4 inhibitors: } \\
7.8 \text {, placebo: } 7.7^{\star}\end{array}$ & $\begin{array}{l}\text { DDP-4 inhibitors: } 75 \text {, } \\
\text { placebo: } 75^{*}\end{array}$ & $\begin{array}{l}\text { DDP-4 } \\
\text { inhibitors: } 72 \text {, } \\
\text { placebo: } 62^{\star}\end{array}$ & $\begin{array}{l}\text { Plasma glucose } \leq 3.9 \\
\mathrm{mmol} / \mathrm{L} \text {, with or without } \\
\text { symptoms }\end{array}$ \\
\hline Chacra et al ${ }^{45}$ & 24 & $\begin{array}{l}\text { Saxagliptin } 2.5 \mathrm{mg} \\
(n=248) \text {, saxagliptin } 5 \mathrm{mg} \\
(n=253) \text {, or placebo } \\
(n=267)\end{array}$ & Glyburide & $\begin{array}{l}\text { DDP-4 inhibitors: } \\
8.4-8.5 \text {, placebo: } \\
8.4\end{array}$ & $\begin{array}{l}\text { DDP-4 inhibitors: } 55 \text {, } \\
\text { placebo: } 55\end{array}$ & $\begin{array}{l}\text { DDP-4 } \\
\text { inhibitors: } 45 \text {, } \\
\text { placebo: } 46\end{array}$ & NR \\
\hline Garber et al ${ }^{46}$ & 24 & $\begin{array}{l}\text { Vildagliptin } 50 \mathrm{mg} \\
(n=170) \text { or } 100 \mathrm{mg} \\
(n=169), \text { or placbeo } \\
(n=176)\end{array}$ & Glimepiride & $\begin{array}{l}\text { DDP-4 inhibitors: } \\
\text { 8.5-8.6, placebo: } \\
8.5\end{array}$ & $\begin{array}{l}\text { DDP-4 inhibitors: } \\
\text { 58-59, placebo: } 58\end{array}$ & $\begin{array}{l}\text { DDP-4 } \\
\text { inhibitors: } 59 \text {, } \\
\text { placebo: } 58\end{array}$ & $\begin{array}{l}\text { Symptomatic } \\
\text { hypoglycaemia confirmed } \\
\text { by self monitored blood } \\
\text { glucose }<3.1 \mathrm{mmol} / \mathrm{L}\end{array}$ \\
\hline $\begin{array}{l}\text { Hermansen } \\
\text { et } \mathrm{al}^{47}\end{array}$ & 24 & $\begin{array}{l}\text { Sitagliptin } 100 \mathrm{mg} \\
(\mathrm{n}=222) \text { or placebo } \\
(\mathrm{n}=219)\end{array}$ & Glimepiride & $\begin{array}{l}\text { DDP-4 inhibitors: } \\
\text { 8.3, placebo: } 8.3\end{array}$ & $\begin{array}{l}\text { DDP-4 inhibitors: } \\
\text { 56, placebo: } 56.5\end{array}$ & $\begin{array}{l}\text { DDP-4 } \\
\text { inhibitors: } 53 \text {, } \\
\text { placebo: } 53\end{array}$ & $\begin{array}{l}\text { NR, but hypoglycaemia is } \\
\text { included in adverse } \\
\text { events of special interest }\end{array}$ \\
\hline Kikuchi et al ${ }^{48}$ & 12 & $\begin{array}{l}\text { Vildagliptin } 100 \mathrm{mg} \\
(n=102) \text { or placebo } \\
(n=100)\end{array}$ & Glimepiride & $\begin{array}{l}\text { DDP-4 inhibitors: } \\
\text { 7.8, placebo: } 8.0\end{array}$ & $\begin{array}{l}\text { DDP-4 inhibitors: } 59 \text {, } \\
\text { placebo: } 60\end{array}$ & $\begin{array}{l}\text { DDP-4 } \\
\text { inhibitors: } 73.5 \text {, } \\
\text { placebo: } 69\end{array}$ & $\begin{array}{l}\text { Symptomatic } \\
\text { hypoglycaemia, } \\
\text { confirmed by self } \\
\text { monitored blood glucose } \\
<3.1 \mathrm{mmol} / \mathrm{L}\end{array}$ \\
\hline Lewin et al ${ }^{49}$ & 18 & $\begin{array}{l}\text { Linagliptin } 5 \mathrm{mg}(\mathrm{n}=161) \\
\text { or placebo }(n=84)\end{array}$ & $\begin{array}{l}\text { Sulphonylureas, not } \\
\text { specified }\end{array}$ & $\begin{array}{l}\text { DDP-4 inhibitors: } \\
\text { 8.6, placebo: } 8.6\end{array}$ & $\begin{array}{l}\text { DDP-4 inhibitors: } 57, \\
\text { placebo: } 56\end{array}$ & $\begin{array}{l}\text { DDP-4 } \\
\text { inhibitors: } 48, \\
\text { placebo: } 62\end{array}$ & $\begin{array}{l}\text { NR, but hypoglycaemia } \\
\text { was recorded and } \\
\text { analysed separately from } \\
\text { other adverse events }\end{array}$ \\
\hline Owens et al ${ }^{50}$ & 24 & $\begin{array}{l}\text { Linagliptin } 5 \text { mg }(m=792) \\
\text { or placebo }(m=263)\end{array}$ & $\begin{array}{l}\text { Sulphonylureas, not } \\
\text { specified }\end{array}$ & $\begin{array}{l}\text { DDP-4 inhibitors: } \\
\text { 8.1, placebo: } 8.1\end{array}$ & $\begin{array}{l}\text { DDP-4 inhibitors: } \\
\text { 58, placebo: } 58\end{array}$ & $\begin{array}{l}\text { DDP-4 } \\
\text { inhibitors: } 48, \\
\text { placebo: } 47\end{array}$ & NR \\
\hline Pratley et al ${ }^{51}$ & 26 & $\begin{array}{l}\text { Alogliptin } 12.5 \mathrm{mg} \\
(n=203), \text { a logliptin } 25 \mathrm{mg} \\
(n=198), \text { or placebo } \\
(m=99)\end{array}$ & Glyburide & NR & $\begin{array}{l}\text { DDP-4 inhibitors: } \\
\text { 56.5, placebo: } 57\end{array}$ & $\begin{array}{l}\text { DDP-4 } \\
\text { inhibitors: } 52 \text {, } \\
\text { placebo: } 51.5\end{array}$ & $\begin{array}{l}\text { Symptomatic } \\
\text { hypoglycaemia with } \\
\text { blood glucose }<3.3 \\
\mathrm{mmol} / \mathrm{L} \text { or }<2.8 \mathrm{mmol} / \mathrm{L} \\
\text { without symptoms }\end{array}$ \\
\hline Seino et al ${ }^{52}$ & 12 & $\begin{array}{l}\text { Alogliptin } 12.5 \mathrm{mg} \\
(n=105) \text {, alogliptin } 25 \mathrm{mg} \\
(n=104) \text {, or placebo } \\
(n=103)\end{array}$ & Glimepiride & $\begin{array}{l}\text { DDP-4 inhibitors: } \\
8.5 \% \text {, placebo: } \\
8.6 \%\end{array}$ & $\begin{array}{l}\text { DDP-4 inhibitors: } \\
60 \text {, placebo: } 60\end{array}$ & $\begin{array}{l}\text { DDP-4 } \\
\text { inhibitors: } 66, \\
\text { placebo: } 69\end{array}$ & NR \\
\hline White et al ${ }^{53}$ & $76 \dagger$ & $\begin{array}{l}\text { Alogliptin any doses } \\
(n=1198) \text {, or placebo } \\
(n=1172)\end{array}$ & $\begin{array}{l}\text { Sulphonylureas, not } \\
\text { specified }\end{array}$ & $\begin{array}{l}\text { DDP-4 inhibitors: } \\
\text { 8.0, placebo: } 8.0^{*}\end{array}$ & $\begin{array}{l}\text { DDP-4 inhibitors: } 61 \text {, } \\
\text { placebo: } 61 \neq\end{array}$ & $\begin{array}{l}\text { DDP-4 } \\
\text { inhibitors: } 68 \text {, } \\
\text { placebo: } 69^{*}\end{array}$ & NR \\
\hline
\end{tabular}




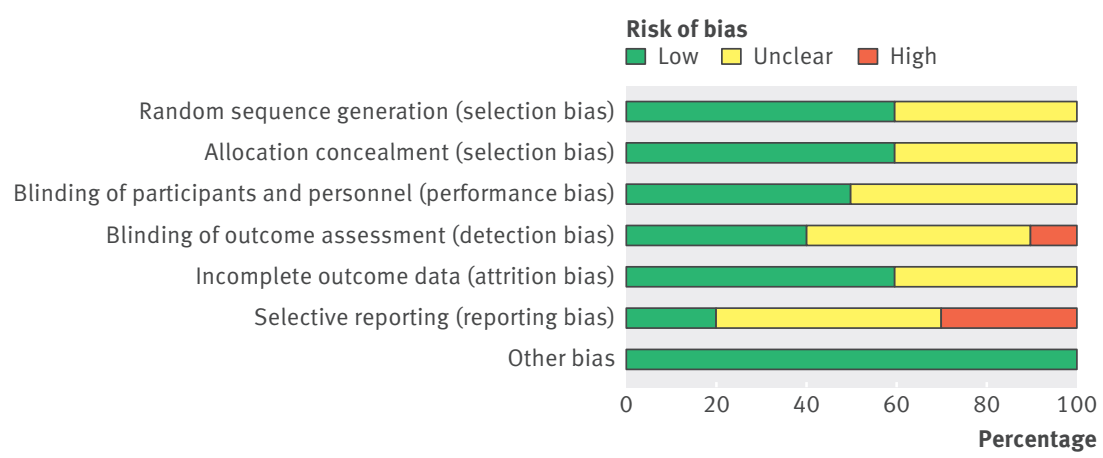

Fig 2 | Risk of bias assessment across included studies

Meta-analysis

The risk ratio of hypoglycaemia for DPP-4 inhibitors at any dose plus sulphonylureas versus placebo plus sulphonylureas was 1.52 (95\% confidence interval 1.29 to 1.80 ), with no evidence of heterogeneity across the trials $\left(\mathrm{Q}=11.2, \mathrm{P}=0.26, \mathrm{I}^{2}=20 \%\right.$; fig 3$)$.

The NNH was 17 (95\% confidence interval 11 to 30) for a treatment duration of six months or less, 15 (9 to 26) for 6.1 to 12 months, and 8 ( 5 to 15 ) for more than one year.

When trials with a high risk of detection bias and reporting bias were excluded from the analysis, the pooled risk ratio was 1.40 (1.18 to 1.67; see supplementary figure 1). The risk ratio was 1.61 (1.30 to 2.00 ) when trials that allowed the use of insulin were excluded. The risk ratio was similar to that of the principal analysis when trials in which an apparent imbalance in sex ratio were excluded (1.52, 1.27 to $1.81 ; \mathrm{Q}=10.70, \mathrm{P}=0.15$; $I^{2}=35 \%$; see supplementary figure 2 ). The pooled risk ratio in trials reporting a definition of hypoglycaemia was 1.54 ( 0.99 to $2.42 ; \mathrm{Q}=2.1, \mathrm{P}=0.5, \mathrm{I}^{2}=0 \%$ ), whereas in those in which a definition was not reported it was 1.52 (1.27 to 1.82; $\mathrm{Q}=9.1, \mathrm{P}=0.10, \mathrm{I}^{2}=45 \%$ ); these two groups of trials did not differ $\left(\mathrm{Q}=0.0, \mathrm{P}=0.95, \mathrm{I}^{2}=0 \%\right.$; see supplementary figure 3).

In subgroup analysis, there was no difference between low and full dose DPP-4 inhibitors for risk of hypoglycaemia $\left(\mathrm{Q}=0.99, \mathrm{P}=0.32, \mathrm{I}^{2}=0 \%\right.$; fig 4 ). The risk for DPP-4 inhibitors remained statistically significantly increased at full dose $(1.66,1.34$ to 2.06$)$, but not at low dose (1.33, 0.92 to 1.94; fig 4). For DPP-4 inhibitors full dose plus sulphonylureas, the NNH was 13 (8 to 25) for a treatment duration of six months or less, 11 (7 to 22) for 6.1 to 12 months, and 7 ( 4 to 13) for more than one year.

No clear evidence of publication bias was found on visual inspection of the funnel plot (fig 5), and the Egger test showed no asymmetry $(\mathrm{z}=1.3 ; \mathrm{P}=0.2)$. The strength of evidence of this meta-analysis was evaluated as high according to GRADE (table 2).

\section{Discussion}

In this meta-analysis we found about a 50\% increase in the risk of hypoglycaemia when a dipeptidyl
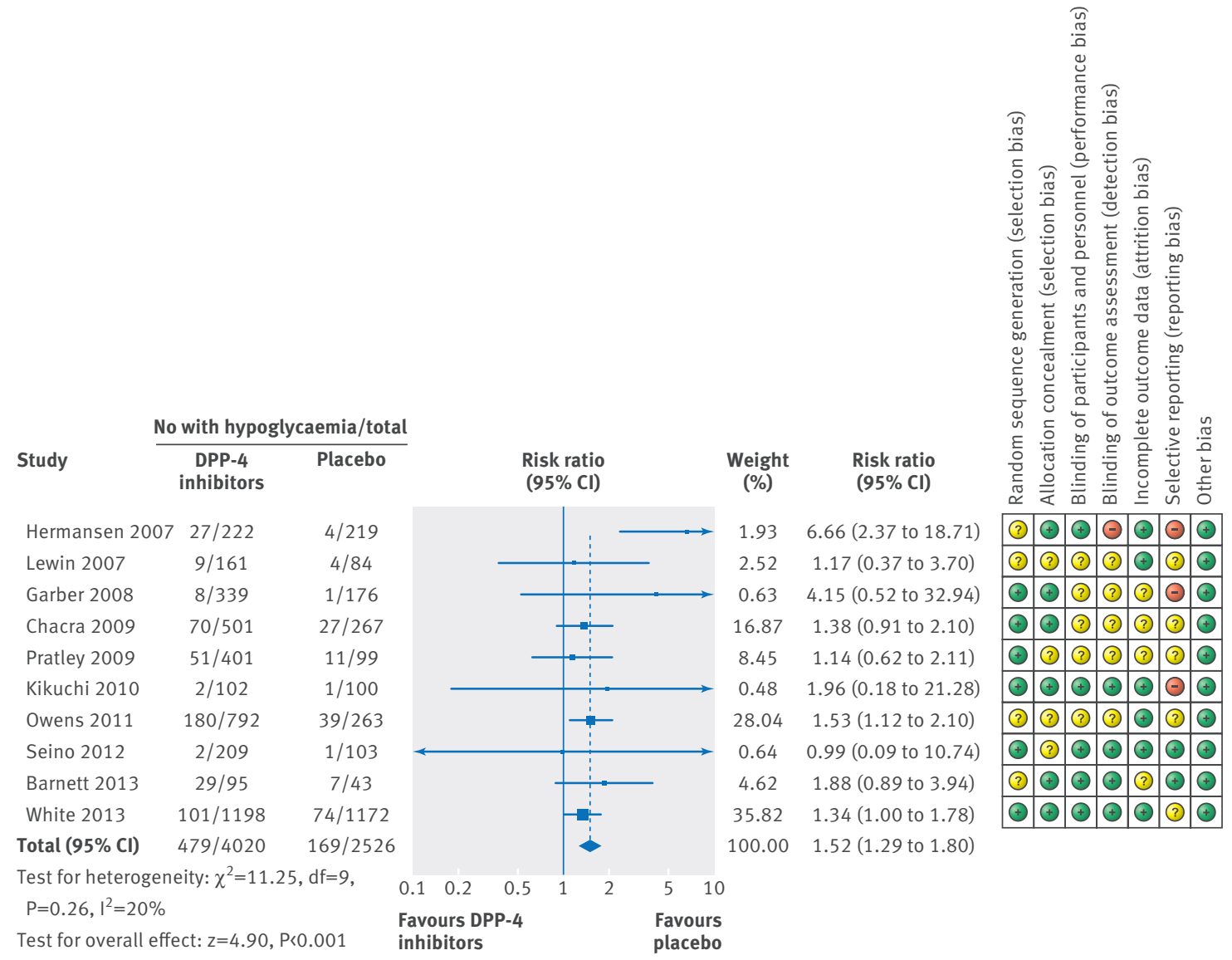

Fig 3 | Forest plot showing risk of hypoglycaemia in patients treated with dipeptidyl peptidase-4 (DPP-4) inhibitors plus sulphonylureas compared with placebo plus sulphonylureas 
peptidase-4 (DPP-4) inhibitor was added to sulphonylureas to treat people with type 2 diabetes, leading to one excess case of hypoglycaemia for every 17 patients in the first six months of treatment. This risk was confirmed for full doses of DPP-4 inhibitors, whereas it could not be excluded for lower doses.

DPP-4 inhibitors act indirectly on insulin levels by enforcing the incretin effect, which is a response to high oral intake of carbohydrates and fatty acids. ${ }^{20}$ Such drugs should therefore act on glycaemia only in response to such intakes, thereby protecting patients from hypoglycaemia. However, in patients treated with sulphonylureas, insulin secretion is already stimulated independently of glycaemia and the addition of a reinforced incretin effect on insulin levels leads to an increase in the risk of hypoglycaemia. Given the frequency of this relevant event in people with type 2 diabetes treated with sulphonylureas, the risk associated with the addition of DPP-4 inhibitors would lead to a huge number of cases of induced hypoglycaemia, some of which could be severe. ${ }^{545}$ The present meta-analysis did not allow investigation of the threshold of dose combinations (DPP-4 inhibitors plus sulphonylureas) associated with an increased risk of hypoglycaemia; an individual patient meta-analysis could be helpful in this regard.

The risk of hypoglycaemia related to the addition of a DPP-4 inhibitor to sulphonylurea is acknowledged in the summaries of product characteristics for DPP-4 inhibitors; most recommend using full dose DPP-4 inhibitors but a reduced sulphonylurea dose in patients taking such combinations, although the magnitude of reduction is not stated. ${ }^{30-34}$ Currently, to what extent this recommendation would lower the number of excess cases of induced hypoglycaemia is unknown. Notably, the suggested individual patient meta-analysis would
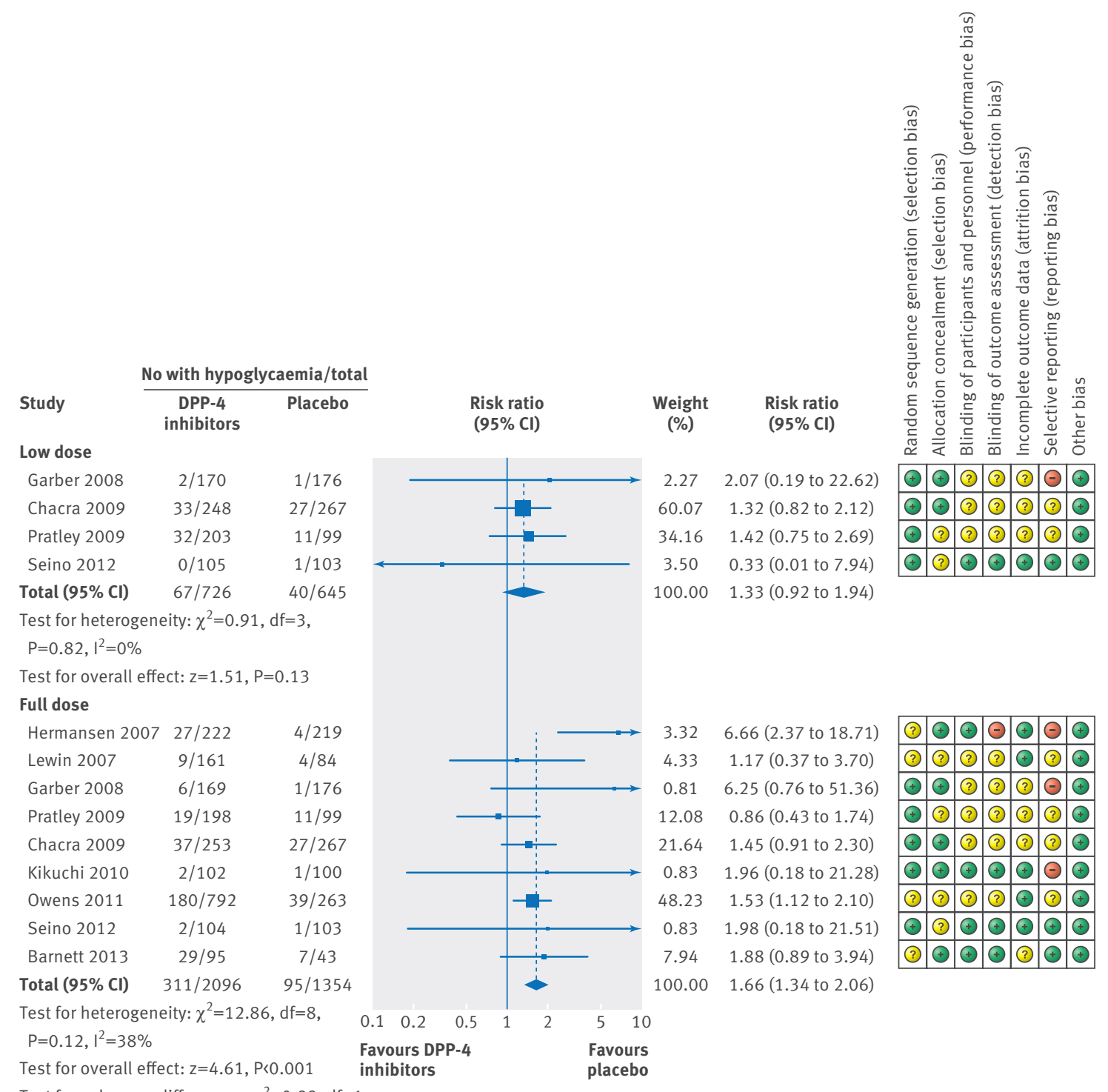

$P=0.32,\left.\right|^{2}=0 \%$

Fig 4 | Forest plot showing risk of hypoglycaemia in patients treated with full or low dose dipeptidyl peptidase-4 (DPP-4) inhibitors plus sulphonylureas compared with placebo plus sulphonylureas 


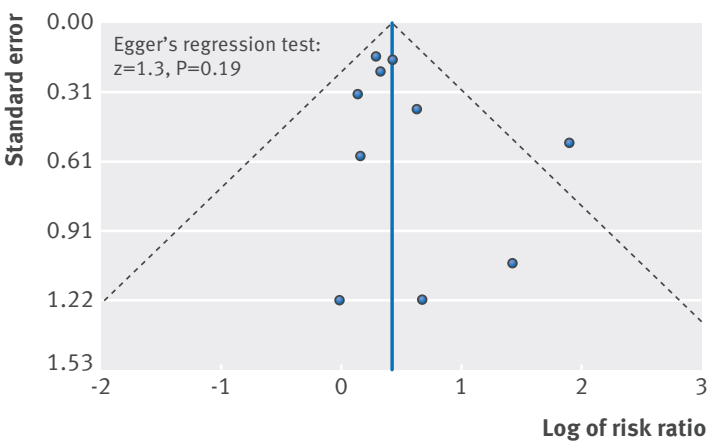

Fig 5 | Funnel plot for publication bias. Scatter plot reporting risk ratio of the studies testing dipeptidyl peptidase-4 (DPP-4) inhibitors plus sulphonylureas compared with placebo plus sulphonylureas (horizontal axis) against their standard error (vertical axis)

not fill this knowledge gap as the effect of reducing the dose of sulphonylureas has not been investigated in trials studying DPP-4 inhibitors.

For low doses of DPP-4 inhibitors (half the full dose when applicable), the increase in hypoglycaemia risk was not statistically significant. However, the existence of this risk cannot be fully ruled out by the present results, and a larger sample would be required to increase the precision of the estimates. Furthermore, although the point estimate was lower (risk ratio $1.33 \mathrm{v}$ 1.66 for full doses), which suggests a potential dose effect, no heterogeneity was found between low and full doses of DPP-4 inhibitors, yet this could result from a lack of power in the heterogeneity test (low dose group was half the size of the high dose group).

\section{Strengths and limitations of this study}

The present analysis has important strengths. Firstly, it is based on a large sample of patients; over 4000 treated with a combination of DPP-4 inhibitors and sulphonylureas, and over 2500 treated with placebo and sulphonylureas. Secondly, the quality of each study included was high according to the Cochrane Collaboration tool for risk of bias assessment. The present meta-analysis used data concerning all currently marketed DPP-4 inhibitors (alogliptin, linagliptin, saxagliptin, sitagliptin, and vildagliptin), and results were consistent within studies, with no heterogeneity being found among estimates. Thirdly, there was no evidence of publication bias; the funnel plot was balanced and the Egger test was not statistically significant. Overall, the quality of evidence provided by the present meta-analysis was assessed as high according to GRADE.

Nevertheless, the meta-analysis does have certain limitations. Firstly, in the main analysis we included certain studies that presented a high risk for detection and reporting bias, ${ }^{46-48}$ but exclusion of these studies did not meaningfully change the pooled estimates. Secondly, three studies could not be included because data were not available for the risk of hypoglycaemia in patients receiving sulphonylureas. $56-58$ However, in view of the GRADE framework, including results from these studies would be unlikely to change the results owing to the size of the present meta-analysis, the high number of hypoglycaemia cases, and the confidence intervals of the pooled risk ratio that clearly do not cross the line of no effect. ${ }^{36}$ The absence of heterogeneity in estimates found from the 10 included studies further supports this hypothesis. Thirdly, the results of this meta-analysis are dominated by the results of three studies that account for more than $80 \%$ of the pooled results of the principal analysis; 45053 a sensitivity analysis without these studies did not substantially change the results of the meta-analysis (data not shown). Fourthly, the definition of hypoglycaemia varied among the included randomised controlled trials, and it was not reported in six. Other authors did not perform a meta-analysis on hypoglycaemia risk on the basis of this lack of homogeneity in its definition across the tri$\mathrm{als}^{23}$; nevertheless, in the present analysis this could be considered as a minor limitation, as the risk did not differ between trials with or without a clear definition of hypoglycaemia. The incidence of hypoglycaemia also varied among studies; however, this did not have any impact on the estimation of the pooled risk (no statistical heterogeneity was found) nor on the number needed to treat to harm (NNH) calculation, which was based on an external assumed control risk of hypoglycaemia retrieved from 27 clinical studies included in a meta-analysis in the Cochrane Library. ${ }^{29}$ In the present study, the pooled risk ratio was retrieved mainly from studies with a follow-up of less than six months. Thus, the NNH calculation for other study durations is based on the assumption of a constant risk over time. In the absence of relevant data, the most reliable estimation of $\mathrm{NNH}$ is that reported for the first six months of treatment.

\section{Clinical importance}

It is important to underline that hypoglycaemia is the most common adverse reaction related to glucose lower-

\begin{tabular}{|c|c|c|c|c|c|c|c|c|c|c|}
\hline \multicolumn{5}{|c|}{ Quality assessment } & \multicolumn{2}{|c|}{ No (\%) of patients } & \multicolumn{2}{|l|}{ Effect } & \multirow[b]{2}{*}{ Quality } & \multirow[b]{2}{*}{ Importance } \\
\hline $\begin{array}{l}\text { Risk of } \\
\text { bias }\end{array}$ & Inconsistency & Indirectness & Imprecision & Other considerations & All studies & Placebo & $\begin{array}{l}\text { Relative risk } \\
(95 \% \mathrm{Cl})\end{array}$ & $\begin{array}{l}\text { Absolute risk } \\
(95 \% \mathrm{Cl})\end{array}$ & & \\
\hline $\begin{array}{l}\text { Not } \\
\text { serious* }\end{array}$ & Not serioust & Not serious & Not serious $¥$ & $\begin{array}{l}\text { Dose-response } \\
\text { gradient }\end{array}$ & $\begin{array}{l}479 / 4020 \\
(11.9)\end{array}$ & $\begin{array}{l}169 / 2526 \\
(6.7)\end{array}$ & $\begin{array}{l}1.52 \\
(1.29 \text { to } 1.80)\end{array}$ & $\begin{array}{l}35 \text { more per } 1000 \\
\text { (from } 19 \text { more to } 54 \\
\text { more) }\end{array}$ & High & Critical§ \\
\hline
\end{tabular}

*Only three studies were judged to have a high risk of detection bias. Among them, a high risk of reporting bias was found in one study. Nevertheless, when these studies were excluded from analysis, the result did not change substantially.

+No heterogeneity was found among estimates.

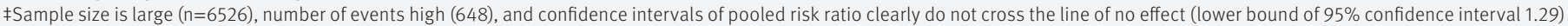
$\S$ Hypoglycaemia is the most common adverse reaction related to glucose lowering treatment. It increases the risk of all cause mortality and cardiovascular events. Symptoms related to

hypoglycaemia (eg, nervousness, sweating, trembling, weakness, palpitations) affect quality of life. 
ing drugs and in itself is a serious clinical event. Even when not directly life threatening, it is associated with an increased risk of all cause mortality, cardiovascular disease, cardiovascular mortality, and hospital admission. ${ }^{236}$ Moreover, hypoglycaemia stimulates both the sympathetic and the renin-angiotensin-aldosterone systems and thus results in symptomatic heart failure and hospital admission in at risk individuals. ${ }^{85}$ This is an important factor of which clinicians should be aware. In addition, hypoglycaemia and its related symptoms (eg, nervousness, sweating, trembling, weakness, palpitations) negatively affect quality of life and disrupt many daily activities such as driving, work performance, and leisure activities. ${ }^{10}{ }^{11}$ More importantly, mild to moderate iatrogenic hypoglycaemia can decrease the usual adrenergic response to hypoglycaemia. ${ }^{13}$ This may cause hypoglycaemia unawareness and compromise behavioural defences (hunger resulting in sugar ingestion), which in turn can lead to severe hypoglycaemia. ${ }^{1617}$ It is thus important to lower the risk of mild to moderate hypoglycaemia, which remains a serious adverse event. Adequate information about the risk of hypoglycaemia, whatever its severity, should thus be considered of primary importance for patients and health professionals involved in the management of people with diabetes. Reaching good glycated haemoglobin levels should not be at the expense of hypoglycaemic events, which could outweigh the benefit of preventing risks associated with raised blood glucose concentrations. Thus, the risk shown by the findings in this systematic review and meta-analysis for all severities of hypoglycaemia should not be minimised by considering that only severe episodes would be of clinical concern.

\section{Conclusions}

This meta-analysis found about a 50\% increase in the risk of hypoglycaemia associated with the addition of DPP-4 inhibitors to sulphonylureas in people with type 2 diabetes. This adverse event, commonly experienced by people treated for diabetes, would lead to the occurrence of one excess case of hypoglycaemia in every 17 treated patients treated for six months. This potentially represents a huge number of attributable cases worldwide. These results clearly highlight the need to respect existing recommendations for dose reduction of sulphonylureas when initiating treatment with DPP-4 inhibitors, and the urgency to determine the efficacy of this measure in minimising the risk of hypoglycaemia.

Contributors: FS conceived and designed the study; acquired, analysed, and interpreted the data; and drafted the article. He had full access to all the data in the study and takes responsibility for the integrity of the data and the accuracy of the data analysis. NM conceived and designed the study, and analysed and interpreted the data. MA and PR analysed and interpreted the data. ER and FDP conceived and designed the study, and interpreted the data. BB conceived and designed the study, and analysed and interpreted the data. AP conceived and designed the study; acquired and interpreted the data; drafted the article; and investigated the accuracy and integrity of any part of the work. AP is the guarantor. All authors revised the article critically for important intellectual content and gave final approval of the version to be published.

Funding: This study was not funded (Philip Robinson holds the position of medical writer and is employed as such by the University of Bordeaux pharmacology department). All the researchers involved performed this study in the context of their research activities. The authors would like to thank the EXAMINE study group for the availability of the data related to the EXAMINE trial.

Competing interests: All authors have completed the ICMJE uniform disclosure form at www.icmje.org/coi_disclosure.pdf (available on request from the corresponding author) and declare: no support from any organisation for the submitted work. FS, MA, ER, FdP, and BB, and have no financial relationships with any organisations that might have an interest in the submitted work in the previous three years. NM and PR have had specified relationships on other matters with Novartis and Takeda, which might have an interest in the submitted work. AP has had specified relationships on other matters with Novartis, which might have an interest in the submitted work. BB, NM, and AP have had specified relationships on other matters with public regulatory agencies and with health care insurance systems that might have an interest in the submitted work. All authors declare no other relationships or activities that could appear to have influenced the submitted work.

Ethical approval: Not required.

Data sharing: No additional data available.

Transparency: FS (corresponding author) and AP (manuscript's guarantor) affirm that the manuscript is honest, accurate, and transparent, and that no important aspects of the study have been omitted.

This is an Open Access article distributed in accordance with the Creative Commons Attribution Non Commercial (CC BY-NC 3.0) license, which permits others to distribute, remix, adapt, build upon this work non-commercially, and license their derivative works on different terms, provided the original work is properly cited and the use is non-commercial. See: http://creativecommons.org/licenses/ by-nc/3.0/.

1 Kilbridge PM, Campbell UC, Cozart HB, Mojarrad MG. Automated surveillance for adverse drug events at a community hospital and an academic medical center. J Am Med Inform Assoc 2006;13:372-7. doi:10.1197/jamia.M2069.

2 Goto A, Arah OA, Goto M, Terauchi Y, Noda M. Severe hypoglycaemia and cardiovascular disease: systematic review and meta-analysis with bias analysis. BMJ 2013;347:f4533. doi:10.1136/bmj.f4533.

3 Currie CJ, Peters JR, Tynan A, et al. Survival as a function of $\mathrm{HbA}(1 \mathrm{c})$ in people with type 2 diabetes: a retrospective cohort study. Lancet 2010;375:481-9. doi:10.1016/S0140-6736(09)61969-3.

4 Bonds DE, Miller ME, Bergenstal RM, et al. The association between symptomatic, severe hypoglycaemia and mortality in type 2 diabetes: retrospective epidemiological analysis of the ACCORD study. BMJ 2010:340:b4909. doi:10.1136/bmj.b4909.

5 Gerstein HC, Miller ME, Genuth S, et al. ACCORD Study Group. Long-term effects of intensive glucose lowering on cardiovascular outcomes. N Engl / Med 2011;364:818-28. doi:10.1056/ NEIMoa1006524.

6 Huang ES, Laiteerapong N, Liu JY, John PM, Moffet HH, Karter AJ. Rates of complications and mortality in older patients with diabetes mellitus: the diabetes and aging study. JAMA Intern Med 2014:174:251-8 doi:10.1001/jamainternmed 2013.12956.

7 Budnitz DS, Lovegrove MC, Shehab N, Richards CL. Emergency hospitalizations for adverse drug events in older Americans. N Engl J Med 2011:365:2002-12 doi:10.1056/NEIMsa1103053.

8 Gilbert RE, Krum H. Heart failure in diabetes: effects of antihyperglycaemic drug therapy. Lancet 2015;385:2107-17. doi:10.1016/ S0140-6736(14)61402-1.

9 Johnston SS, Conner C, Aagren M, Ruiz K, Bouchard J. Association between hypoglycaemic events and fall-related fractures in Medicare-covered patients with type 2 diabetes. Diabetes Obes Metab 2012:14:634-43. doi:10.1111/j.1463-1326.2012.01583x.

10 Lorber D, Anderson J, Arent S, et al. American Diabetes Association. Diabetes and driving. Diabetes Care 2012;35(Suppl 1):S81-6. doi:10.2337/dc12-s081

11 Frier BM. Hypoglycaemia in diabetes mellitus: epidemiology and clinical implications. Nat Rev Endocrinol 2014;10:711-22. doi:10.1038/nrendo.2014.170.

12 International Hypoglycaemia Study Group. Minimizing hypoglycemia in diabetes. Diabetes Care 2015;38:1583-91. doi:10.2337/dc15-0279.

13 Harrison TR. Harrison's principles of internal medicine. French 18th Edition. McGraw-Hill, 1970.

14 Cryer PE. Hypoglycemia-associated autonomic failure in diabetes. Handb Clin Neurol 2013;117:295-307. doi:10.1016/ B978-0-444-53491-0.00023-7.

15 Cryer PE. Mechanisms of hypoglycemia-associated autonomic failure in diabetes. N Engl / Med 2013;369:362-72. doi:10.1056/ NEJMra1215228.

16 Sen Gupta P, Green AN, Chowdhury TA. Hypoglycaemia. BM] 2011;342:d567. doi:10.1136/bmj.d567.

17 Cove DH. Hypoglycaemia unawareness. BMJ 2011;342:d1474. doi:10.1136/bmj.d1474 
18 Cariou B, Charbonnel B, Staels B. Thiazolidinediones and PPAR $\gamma$ agonists: time for a reassessment. Trends Endocrinol Metab 2012;23:205-15. doi:10.1016/j.tem.2012.03.001.

19 Kirpichnikov D, McFarlane SI, Sowers JR. Metformin: an update. Ann Intern Med 2002;137:25-33. doi:10.7326/0003-4819-137-1-200207020-00009.

20 Drucker DJ. Biological actions and therapeutic potential of the glucagon-like peptides. Gastroenterology 2002;122:531-44. doi:10.1053/gast.2002.31068.

21 Mclntosh CH, Demuth HU, Pospisilik JA, Pederson R. Dipeptidyl peptidase IV inhibitors: how do they work as new antidiabetic agents?Regul Pept 2005;128:159-65. doi:10.1016/j. regpep.2004.06.001.

22 Campbell RK. Glimepiride: role of a new sulfonylurea in the treatment of type 2 diabetes mellitus. Ann Pharmacother 1998;32:1044-52. doi:10.1345/aph.17360.

23 Karagiannis T, Paschos P, Paletas K, Matthews DR, Tsapas A. Dipeptidyl peptidase- 4 inhibitors for treatment of type 2 diabetes mellitus in the clinical setting: systematic review and meta-analysis. BMJ 2012:344:e1369 doi:101136/bmi.e1369.

24 Keating GM. Alogliptin: a review of its use in patients with type 2 diabetes mellitus. Drugs 2015;75:777-96. doi:10.1007/ s40265-015-0385-y.

25 Forst T, Koch C, Dworak M. Vildagliptin versus insulin in patients with type 2 diabetes mellitus inadequately controlled with sulfonylurea: results from a randomized, 24 week study. Curr Med Res Opin 2015;31:1079-84. doi:10.1185/03007995.2015.1039936.

26 Richter B, Bandeira-Echtler E, Bergerhoff K, Lerch CL. Dipeptidyl peptidase-4 (DPP-4) inhibitors for type 2 diabetes mellitus. Cochrane Database Syst Rev 2008;(2):CD006739.

27 Barnett AH, Huisman H, Jones R, von Eynatten M, Patel S, Woerle HJ. Linagliptin for patients aged 70 years or older with type 2 diabetes inadequately controlled with common antidiabetes treatments: a randomised, double-blind, placebo-controlled trial. Lancet 2013;382:1413-23. doi:10.1016/S0140-6736(13)61500-7.

28 Salvo F, Moore N, Pariente A. Linagliptin for elderly patients with type 2 diabetes. Lancet 2014;383:307. doi:10.1016/

S0140-6736(14)60103-3

29 Hemmingsen B, Schroll JB, Lund SS, et al. Sulphonylurea monotherapy for patients with type 2 diabetes mellitus. Cochrane Database Syst Rev 2013;4:CD009008.

30 Takeda. Summary of Product Characteristics. Vipidia. Last access date 05/12/2014. Secondary Takeda. Summary of Product Characteristics. Vipidia. Last access date 05/12/2014. www.ema.europa.eu/docs/ en_GB/document_library/EPAR_-_Product_Information/ human/002182/WC500152271.pdf.

31 Ingelheim B. Summary of Product Characteristics. Trajenta. Last access date 05/12/2014. Secondary Boehringer Ingelheim. Summary of Product Characteristics. Trajenta. Last access date 05/12/2014. www.ema.europa.eu/docs/en_GB/document_library/EPAR_-Product Information/human/002110/WC500115745.pdf.

32 AstraZeneca. Summary of Product Characteristics. Onglyza. Last access date 05/12/2014. Secondary AstraZeneca. Summary of Product Characteristics. Onglyza. Last access date 05/12/2014. www. ema.europa.eu/docs/en_GB/document_library/EPAR_-_Product_ Information/human/001039/WC500044316.pdf.

33 Merck Sharp \& Dohme. Summary of Product Characteristics. Januvia. Last access date 05/12/2014. Secondary Merck Sharp \& Dohme. Summary of Product Characteristics. Januvia. Last access date 05/12/2014. www.ema.europa.eu/docs/en_GB/document_ library/EPAR - Product Information/human/000722/ WC500039054.pdf.

34 Novartis. Summary of Product Characteristics. Galvus. Last access date 05/12/2014. Secondary Novartis. Summary of Product Characteristics. Galvus. Last access date 05/12/2014. www.ema. europa.eu/docs/en_GB/document_library/EPAR_-_Product_ Information/human/000771/WC500020327.pdf.

35 Higgins JP, Altman DG, Gøtzsche PC, et al. Cochrane Bias Methods Group Cochrane Statistical Methods Group. The Cochrane Collaboration's tool for assessing risk of bias in randomised trials. BMj 2011;343:d5928. doi:10.1136/bmj.d5928.

36 Guyatt GH, Oxman AD, Schünemann HJ, Tugwell P, Knottnerus A. GRADE guidelines: a new series of articles in the Journal of Clinical Epidemiology. J Clin Epidemiol 2011;64:380-2. doi:10.1016/j. jclinepi.2010.09.011.

37 Balshem H, Helfand M, Schünemann HJ, et al. GRADE guidelines: 3. Rating the quality of evidence. J Clin Epidemiol 2011;64:401-6. doi:10.1016/i.jclinepi.2010.07.015.

38 Liberati A, Altman DG, Tetzlaff J, et al. The PRISMA statement for reporting systematic reviews and meta-analyses of studies that evaluate health care interventions: explanation and elaboration. PLoS Med 2009:6:e1000100. doi:10.1371/journal.pmed.1000100.

39 Greenland S. Quantitative methods in the review of epidemiologic literature. Epidemiol Rev 1987;9:1-30.

40 DerSimonian R, Laird N. Meta-analysis in clinical trials. Control Clin Trials 1986;7:177-88. doi:10.1016/0197-2456(86)90046-2.
41 Deeks J), Higgins JPT, Altman DG. Analysing data and undertaking meta-analyses. In: Higgins JPT, Green S, eds. Cochrane Handbook for Systematic Reviews of Interventions Version 5.1.0 (updated March 2011). The Cochrane Collaboration, 2011, Available from handbook.cochrane.org.

42 Higgins JP, Thompson SG. Quantifying heterogeneity in a metaanalysis. Stat Med 2002;21:1539-58. doi:10.1002/sim.1186.

43 Egger M, Davey Smith G, Schneider M, Minder C. Bias in meta-analysis detected by a simple, graphical test. BMJ 1997;315:629-34. doi:10.1136/bmj.315.7109.629.

44 Schünemann HJ, Oxman AD, Vist GE, et al. Interpreting results and drawing conclusions. In: Higgins JPT, Green S, eds. Cochrane Handbook for Systematic Reviews of Interventions Version 5.1.0 (updated March 2011). The Cochrane Collaboration, 2011, Available from handbook.cochrane.org.

45 Chacra AR, Tan GH, Apanovitch A, Ravichandran S, List J, Chen R. CV181-040 Investigators. Saxagliptin added to a submaximal dose of sulphonylurea improves glycaemic control compared with uptitration of sulphonylurea in patients with type 2 diabetes: a randomised controlled trial. Int J Clin Pract 2009;63:1395-406. doi:10.1111/j.1742-1241.2009.02143.x.

46 Garber AJ, Foley JE, Banerii MA, et al. Effects of vildagliptin on glucose control in patients with type 2 diabetes inadequately controlled with a sulphonylurea. Diabetes Obes Metab 2008;10:1047-56. doi:10.1111/j.1463-1326.2008.00859.x.

47 Hermansen K, Kipnes M, Luo E, Fanurik D, Khatami H, Stein P. Sitagliptin Study 035 Group. Efficacy and safety of the dipeptidyl peptidase-4 inhibitor, sitagliptin, in patients with type 2 diabetes mellitus inadequately controlled on glimepiride alone or on glimepiride and metformin. Diabetes Obes Metab 2007;9:733-45. doi:10.1111/j.1463-1326.2007.00744.x.

48 Kikuchi M, Haneda M, Koya D, et al. Efficacy and tolerability of vildagliptin as an add-on to glimepiride in Japanese patients with Type 2 diabetes mellitus. Diabetes Res Clin Pract 2010;89:216-23. doi:10.1016/j.diabres.2010.04.017.

49 Lewin AJ, Arvay L, Liu D, Patel S, von Eynatten M, Woerle HJ. Efficacy and tolerability of linagliptin added to a sulfonylurea regimen in patients with inadequately controlled type 2 diabetes mellitus: an 18-week, multicenter, randomized, double-blind, placebo-controlled trial. Clin Ther 2012;34:1909-19 e15.

50 Owens DR, Swallow R, Dugi KA, Woerle HJ. Efficacy and safety of linagliptin in persons with type 2 diabetes inadequately controlled by a combination of metformin and sulphonylurea: a 24-week randomized study. Diabet Med 2011;28:1352-61 doi:10.1111/j.1464-5491.2011.03387.x.

51 Pratley RE, Kipnes MS, Fleck PR, Wilson C, Mekki Q. Alogliptin Study 007 Group. Efficacy and safety of the dipeptidyl peptidase-4 inhibitor alogliptin in patients with type 2 diabetes inadequately controlled by glyburide monotherapy. Diabetes Obes Metab 2009;11:167-76. doi:10.1111/i.1463-1326.2008.01016x

52 Seino Y, Hiroi S, Hirayama M, Kaku K. Efficacy and safety of alogliptin added to sulfonylurea in Japanese patients with type 2 diabetes: A randomized, double-blind, placebo-controlled trial with an open-label, long-term extension study. J Diabetes Investig 2012;3:517-25. doi:10.1111/j.2040-1124.2012.00226.x.

53 White WB, Cannon CP, Heller SR, et al. EXAMINE Investigators. Alogliptin after acute coronary syndrome in patients with type 2 diabetes. N Engl Med 2013;369:1327-35. doi:10.1056/NEJMoa1305889.

54 Schopman JE, Simon AC, Hoefnagel SJ, Hoekstra JB, Scholten RJ, Holleman F. The incidence of mild and severe hypoglycaemia in patients with type 2 diabetes mellitus treated with sulfonylureas: a systematic review and meta-analysis. Diabetes Metab Res Rev 2014:30:11-22. doi:10.1002/dmrr.2470.

55 Del Prato S, Taskinen MR, Owens DR, et al. Efficacy and safety of linagliptin in subjects with type 2 diabetes mellitus and poor glycemic control: pooled analysis of data from three placebo-controlled phase III trials. J Diabetes Complications 2013:27:274-9. doi:10.1016/j.jdiacomp.2012.11.008.

56 A 24-week, Multicentre, Randomised, Double-Blind, Placebo-Controlled Phase IIIb Study to Evaluate Efficacy and Safety of Saxagliptin in Combination With Metformin and Sulfonylurea in Subjects With Type 2 Diabetes Who Have Inadequate Glycaemic Control With Combination of Metformin and Sulfonylurea. Study number: NCT01128153, 2012.

57 Lukashevich V, Schweizer A, Shao Q, Groop PH, Kothny W. Safety and efficacy of vildagliptin versus placebo in patients with type 2 diabetes and moderate or severe renal impairment: a prospective 24-week randomized placebo-controlled trial. Diabetes Obes Metab 2011:13:947-54. doi:10.1111/j.1463-1326.2011.01467.x.

58 Scirica BM, Bhatt DL, Braunwald E, et al. SAVOR-TIMI 53 Steering Committee and Investigators. Saxagliptin and cardiovascular outcomes in patients with type 2 diabetes mellitus. N Engl J Med 2013·369:1317-26. doi:10.1056/NEJMoa1307684.

59 Hoffman RP. Sympathetic mechanisms of hypoglycemic counterregulation. Curr Diabetes Rev 2007;3:185-93. doi:10.2174/157339907781368995.

(c) BMJ Publishing Group Ltd 2016

Web extra: supplementary information 